\title{
Fatal SARS-CoV-2 coinfection in course of EBV-associated lymphoproliferative disease
}

\author{
Luca Roncati $^{1}$ (D) Beatrice Lusenti ${ }^{1}$. Vincenzo Nasillo ${ }^{1} \cdot$ Antonio Manenti $^{2}$
}

Received: 30 April 2020 / Accepted: 17 May 2020 / Published online: 24 May 2020

(C) Springer-Verlag GmbH Germany, part of Springer Nature 2020

\section{Dear Editor,}

Severe acute respiratory syndrome coronavirus 2 (SARS-CoV-2) is the pathogen responsible for the ongoing pandemic named coronavirus disease 2019 (COVID-19), and new knowledge about this novel virus is needed also through anecdotal cases. A 70-year-old Italian male patient with hepatosplenomegaly and moderate anemia was submitted to full-body computed tomography (CT) scan with contrast medium, which showed multiple supra-/ subdiaphragmatic lymphadenopathies and a right axillary adenomegaly (Fig. 1a); therefore, axillary node and then bone marrow core biopsies were performed. Both the specimens revealed an Epstein-Barr virus (EBV)-associated lymphoproliferative disease (Fig. 1b), with the characteristics of classical Hodgkin lymphoma. Meanwhile, the patient manifested hyperpyrexia accompanied by dyspnea and a nasopharyngeal swab was found positive for SARS-CoV-2. The chest X-ray obtained at the patient's bed in isolation hospital room highlighted a bilateral interstitial pneumonia (Fig. 1c), and the patient died after 13 days from the admission for its complications despite therapy. To date, in about the $10-15 \%$ of affected patients,

Luca Roncati

emailmedical@gmail.com; roncati.luca@aou.mo.it

1 Hemolymphopathology Team, University Hospital of Modena, Modena, Italy

2 Surgery Department, University of Modena and Reggio Emilia, Modena, Italy especially the elderly and those with pre-existing health issues or immunocompromised, COVID-19 can progress from mild symptoms or signs, such as low-grade fever, headache, conjunctivitis, rhinorrhea, anosmia, pharyngodynia, ageusia, cough, chills, myalgia, asthenia, skin rash, nausea vomiting, and diarrhea, to pneumonia, acute respiratory distress syndrome, renal insufficiency, disseminate intravascular coagulation, and multiple organ failure [1]. A marked lymphopenia has been observed in the most serious cases of the disease [2]. EBV belongs to the Herpesviridae family and causes infectious mononucleosis as well as chronic active infections; besides, it can induce various pre-cancerous or cancerous lymphoproliferative disorders, such as mucocutaneous ulcer, Hodgkin lymphoma, Burkitt lymphoma, diffuse large B cell lymphoma, plasmablastic lymphoma, plasma cell myeloma, angioimmunoblastic $\mathrm{T}$ cell lymphoma, follicular $\mathrm{T}$ cell lymphoma, extranodal NK/T cell lymphoma, and aggressive NK cell leukemia, particularly in immunodeficient and/or post-transplanted patients [3]. In these subjects, the synergic action of EBV and SARS-CoV-2 is assumed to be burden by a very high fatality rate. 
Fig. 1 An axial plan of the CT scan with contrast medium shows a $6.5 \times 5.0 \mathrm{~cm}$ mass $(\mathbf{a}$, yellow dashed circle) in the right axillary cable. The in situ hybridization for EBV (EBER probe, $\times 10$ objective) points out several positive blue-stained Hodgkin cells inside the core needle biopsy, taken from the axillary mass (b, on the left), and in the bone marrow specimen $(\mathbf{b}$, on the right). The chest X-ray performed at the patient's bed in isolation hospital room shows a diffuse bilateral interstitial pneumonia (c)

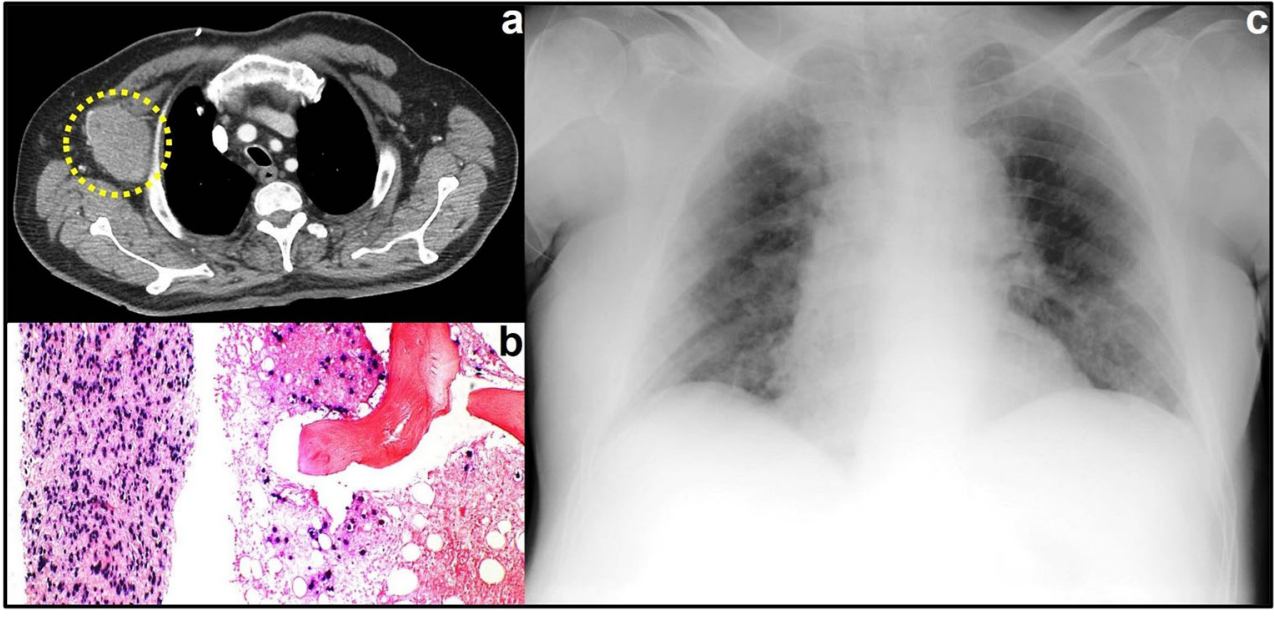

\section{Compliance with ethical standards}

Conflict of interest The authors declare that they have no conflict of interest.

Ethical approval All procedures followed were in accordance with the ethical standards and with the Helsinki Declaration of 1975, as revised in 2008.

Informed consent Not applicable since the patient died.

\section{References}

1. Zhu J, Ji P, Pang J, Zhong Z, Li H, He C, Zhang J, Zhao C (2020) Clinical characteristics of 3,062 COVID-19 patients: a meta-analysis. J Med Virol. https://doi.org/10.1002/jmv.25884

2. Tan L, Wang Q, Zhang D, Ding J, Huang Q, Tang YQ, Wang Q, Miao H (2020) Lymphopenia predicts disease severity of COVID19: a descriptive and predictive study. Signal Transduct Target Ther $5(1): 33$

3. Kim HJ, Ko YH, Kim JE, Lee SS, Lee H, Park G, Paik JH, Cha HJ, Choi YD, Han JH, Huh J (2017) Epstein-Barr virus-associated lymphoproliferative disorders: review and update on 2016 WHO classification. J Pathol Transl Med 51(4):352-358

Publisher's note Springer Nature remains neutral with regard to jurisdictional claims in published maps and institutional affiliations. 